\title{
Diversidade genética de Xylella fastidiosa em regiões produtoras de citros na Bahia
}

\author{
Vinicius Oliveira Casais(1), Epaminondas do Patrocínio(2), Saulo Alves Santos de Oliveira(2), \\ Alessandra Selbach Schnadelbach ${ }^{(1)}$, Cristiane de Jesus Barbosa ${ }^{(2)}$ e Luciana Veiga Barbosa ${ }^{(1)}$
}

\begin{abstract}
(1)Universidade Federal da Bahia, Instituto de Biologia, Laboratório de Genética e Evolução Vegetal, Rua Barão de Jeremoabo, no 147, Campus de Ondina, CEP 40170-290 Salvador, BA, Brasil. E-mail: viniciuscasais@gmail.com, alessandra.schnadelbach@gmail.com, veiga@ufba.br (2)Embrapa Mandioca e Fruticultura, Rua Embrapa, s/no, CEP 44380-000 Cruz das Almas, BA, Brasil. E-mail: epaminondas.patrocinio@embrapa.br, saulo.oliveira@embrapa.br, cristiane.barbosa@embrapa.br
\end{abstract}

Resumo - O objetivo deste trabalho foi avaliar, por meio de marcadores SSR, a diversidade genética de Xylella fastidiosa no Estado da Bahia. Foram estudadas duas das principais regiões produtoras de citros no Estado, o Litoral Norte e o Recôncavo Sul. Para fins comparativos, utilizaram-se dez amostras provenientes do Estado de São Paulo. Foram empregados os seguintes iniciadores: ASSR20, OSSR9, OSSR17, CSSR4, CSSR12 e CSSR20, dos quais os quatro últimos permitiram identificar 22 loci polimórficos. As populações de $X$. fastidiosa presentes em citros no Estado da Bahia apresentam elevada diversidade genética, com base nos marcadores SSR, com pools gênicos distintos e agrupamento geográfico. No Litoral Norte, as populações do isolado apresentam maior diversidade genética do que as da região do Recôncavo Sul da Bahia.

Termos para indexação: Citrus sinensis, bactéria fitopatogênica, CVC, haplótipos, microssatélites.

\section{Genetic diversity of Xylella fastidiosa in citrus producing regions in the state of Bahia, Brazil}

\begin{abstract}
The objective of this work was to evaluate, by SSR markers, the genetic diversity of Xylella fastidiosa in the state of Bahia, Brazil. Two of the main citrus producing regions of the state were evaluated, Litoral Norte and Recôncavo Sul. Ten samples from the state of São Paulo, Brazil, were used for comparison. The following primers were used: ASSR20, OSSR9, OSSR17, CSSR4, CSSR12, and CSSR20, of which the last four allowed the identification of 22 polymorphic loci. The citrus populations of $X$. fastidiosa in the state of Bahia have high genetic diversity, based on SSR markers, with distinct gene pools and geographical grouping. In Litoral Norte, the populations of the isolate show higher genetic diversity than those in the Recôncavo Sul region of Bahia.
\end{abstract}

Index terms: Citrus sinensis, phytopathogenic bacteria, CVC, haplotypes, microsatellites.

\section{Introdução}

Xylella fastidiosa é uma bactéria patogênica, fastidiosa e limitada ao xilema das plantas. Causadora de doenças em diversas culturas agrícolas economicamente importantes, é transmitida por cigarrinhas da família Cicadellidae e Cercopidae e por material propagativo infectado (Janse \& Obradovic, 2010). Xylella fastidiosa subsp. pauca é o agente causal da clorose variegada dos citros (CVC), que afeta, principalmente, as laranjas doces (Citrus sinensis Osbeck) e ocasiona a produção de frutos miúdos, duros e amarelados, imprestáveis para o consumo (Rossetti \& De Negri, 2011). A doença foi inicialmente detectada em São Paulo, em 1987 (Rossetti \& De Negri, 2011). No Estado da Bahia, a doença só foi constatada em 1996, na região do Litoral Norte, e, posteriormente, em
2009, na região do Recôncavo Sul (Santos Filho et al., 2010).

Estudos sobre a diversidade molecular de $X$. fastidiosa subsp. pauca foram realizados por meio de técnicas de RAPD, VNTR, RFLP, SSR e AFLP (Almeida et al., 2008; Kishi et al., 2008), e, mais recentemente, por análises de sequência multilocus (Parker et al., 2012) e comparação de genomas (Varani et al., 2012). Entretanto, no Brasil, a maioria dos isolados de bactérias caracterizados é obtida de pomares nos estados de São Paulo e do Paraná. O conhecimento da diversidade molecular de patógenos de plantas permite entender melhor a distribuição e a epidemiologia da doença causada. Também é um dos requisitos para respaldar ações de defesas fitossanitárias locais e estabelecer estratégias de manejo mais eficientes. 
Apesar de a Bahia e o Sergipe constituírem o segundo maior polo citricultor do Brasil (Instituto Brasileiro de Geografia e Estatística, 2012), quase nenhum trabalho de diversidade genética do agente da CVC foi desenvolvido com isolados obtidos de pomares do Nordeste, com exceção da caracterização de apenas dois isolados oriundos de Sergipe e quatro da Bahia (Mehta et al., 2001; Almeida et al., 2008). Desde a sua constatação em São Paulo, a CVC já causou grandes prejuízos econômicos, e, na Bahia, os únicos danos relatados são de 2008, quando se detectou $20 \%$ de plantas afetadas na região do Litoral Norte do estado (Laranjeira et al., 2008). Contudo, vale ressaltar que, naquele momento, a doença ainda não havia sido relatada na região do Recôncavo Sul (Santos Filho et al., 2010). O último levantamento realizado pela Agência Estadual de Defesa Agropecuária da Bahia (Adab), em 2013, mostrou que a CVC está presente em $84 \%$ dos municípios da região do Litoral Norte e em 32\% dos municípios do Recôncavo Sul (Silva, 2013). Dessa forma, em razão da importância socioeconômica da cultura e da disseminação da doença no Estado da Bahia, há uma demanda de informações técnico-científicas sobre a diversidade genética da bactéria nessas condições.

O objetivo deste trabalho foi avaliar a diversidade genética de $X$. fastidiosa, por meio de marcadores SSR, no Estado da Bahia.

\section{Material e Métodos}

Foram utilizadas plantas de pomares de laranja doce com sintomas da CVC, presentes em duas das principais regiões produtoras de citros do Estado da Bahia - Região do Litoral Norte e Recôncavo Sul-, caracterizadas como de clima tropical quente e úmido. Na região do Litoral Norte, foram selecionados pomares nos municípios

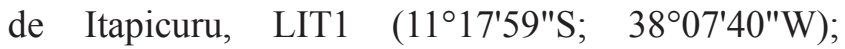

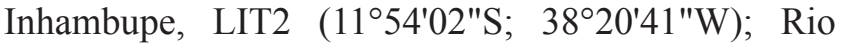

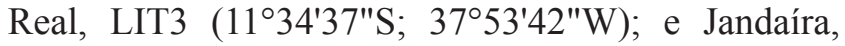

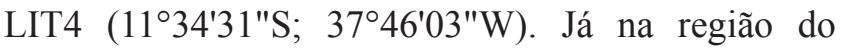
Recôncavo Sul, os pomares foram selecionados em Muritiba, REC1 (12 $37^{\prime} 18^{\prime \prime S}$; 39 $\left.09^{\circ} 56^{\prime \prime W}\right)$ e REC3 (12³6'11"S; 39॰07'37"S); Governador

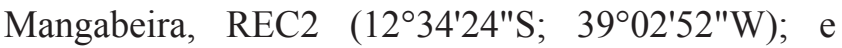
Castro Alves, REC4 (12 $\left.50^{\prime} 07^{\prime \prime} \mathrm{S} ; 3^{\circ} 16^{\prime} 59^{\prime \prime} \mathrm{W}\right)$.

Todos os pomares selecionados estavam formados por plantas de laranja doce 'Pêra-D6', que é uma variedade selecionada pela Embrapa Mandioca e Fruticultura, premunizada com o isolado CTV-D6 do vírus da tristeza dos citros (Citrus tristeza virus, CTV). A principal laranja doce foi plantada nos estados da Bahia e do Sergipe (Vasconcelos et al., 2004). Todas as plantas selecionadas estavam estabelecidas em porta-enxertos de limão-cravo (Citrus limonia Osbeck), cultivar Cravo, com cerca de seis anos de idade. De cada pomar, foram selecionadas cerca de dez plantas com sintomas característicos de clorose variegada na parte superior das folhas, além de manchas marrons na parte inferior da folha, com presença de frutos duros, pequenos e amarelados, em pelo menos dois ramos principais. Em ambas as regiões, foi observada a mesma severidade de sintomas na maioria das plantas amostradas. Cada planta foi considerada como fonte de uma amostra, constituída de dez folhas com sintomas, o que totalizou 41 amostras por região. Para comparação com populações da bactéria presente em São Paulo, principal região produtora do Brasil, também foram utilizadas dez amostras de DNA de $X$. fastidiosa subsp. pauca fornecidas pela Clínica Fitopatológica do Instituto Agronômico de Campinas.

O DNA de cada amostra foi extraído segundo o protocolo de Dellaporta et al. (1983). A comprovação da presença da bactéria nas amostras foi realizada por meio de PCR, com uso dos iniciadores diagnósticos, RST31 e RST33 (Minsavage et al., 1994). Para avaliar a diversidade genética, foram utilizados os iniciadores OSSR9, OSSR17, CSSR4, CSSR12, CSSR20 e ASSR20, já utilizados para a caracterização de polimorfismos em $X$. fastidiosa (Lin et al., 2005). A amplificação via PCR foi realizada conforme Lin et al. (2005), com alterações na temperatura de anelamento, de acordo com o iniciador utilizado. O programa de amplificação consistiu em desnaturação a $95^{\circ} \mathrm{C}$ por $1 \mathrm{~min}$, seguido de 40 ciclos de $95^{\circ} \mathrm{C}$ por $30 \mathrm{~s}, 55^{\circ} \mathrm{C}$ por $30 \mathrm{~s}\left(61^{\circ} \mathrm{C}\right.$ na amplificação com os iniciadores OSSR 17 e CSSR20, e $54^{\circ} \mathrm{C}$ com o iniciador CSSR 12 ), $72^{\circ} \mathrm{C}$ por $45 \mathrm{~s}$ e extensão final de $72^{\circ} \mathrm{C}$ por $5 \mathrm{~min}$. Os produtos obtidos foram avaliados em gel desnaturante de poliacrilamida a $5 \%$, em tampão TBE, a $1.700 \mathrm{~W}$, por $1 \mathrm{~h} 40$ min, e corados com nitrato de prata.

As análises de diversidade genética foram realizadas inter e intrapopulações para $X$. fastidiosa das duas regiões estudadas. Cada pomar selecionado foi considerado uma população. O programa GenAlex 6.2 (Peakall \& Smouse, 2006) foi utilizado para: determinar 
a frequência de loci polimórficos e o número de alelos exclusivos; gerar a matriz de distância baseada na distância e na identidade genética de Nei (Nei, 1978); e para análise molecular de variância (Amova), com auxílio do programa Arlequin 3.5 (Excofier \& Lischer, 2010). O índice de Stoddart \& Taylor, que dá maior peso a genótipos mais frequentes, e o índice de Hills, que dá maior peso a genótipos raros (Grünwald et al., 2003), foram utilizados para analisar a diversidade genética das populações e foram obtidos com uso dos pacotes Vegan e Vegetarian implementados na plataforma $\mathrm{R}$ (R Development Core Team, 2011). A análise fenética, com base no índice de similaridade genética de Nei 'unbiased genetic identity' (Nei, 1978) - e no método de Ward como algoritmo de agrupamento, foi realizada no programa Past (Hammer et al., 2001). O programa Arlequin 3.5 foi empregado no cálculo do minimum spanning tree (MST) e do 'minimum spanning network' (MSN), para determinar a covariância entre as regiões, entre as populações dentro das regiões e entre os indivíduos dentro das populações. A determinação do número de agrupamentos genéticos no conjunto de dados de microssatélites, a partir de abordagem bayesiana, foi realizada no programa Structure 2.3 (Pritchard et al., 2000). O resultado das análises foi submetido à análise no site Structure Harvester, para o cálculo de $\Delta \mathrm{k}$, e no Hapstar 0.7 , para a construção da rede de haplótipos (Teacher \& Griffths, 2011).

\section{Resultados e Discussão}

A presença da bactéria nas plantas selecionadas foi confirmada via PCR, com uso dos iniciadores RST31 e RST33, os quais geraram um fragmento de 733 pares de bases (pb), correspondente a $X$. fastidiosa (Minsavage et al., 1994). Dos iniciadores SSR utilizados, OSSR9 e ASSR20 mostraram padrão monomórfico, já referenciado para o iniciador OSSR9 em trabalhos anteriores (Lin et al., 2005). Os demais iniciadores, CSSR4, CSSR12, CSSR20 e OSSR17, amplificaram 3, 4, 9 e 6 loci, respectivamente, o que totalizou 22 loci analisados. O iniciador CSSR20 (Figura $1 \mathrm{~A}$ ) foi o que detectou o maior número de loci. Resultados semelhantes foram obtidos por Lin et al. (2005) em $X$. fastidiosa caracterizada em diferentes hospedeiros, como espirradeira (Nerium oleander L.), amendoeira (Prunus amygdalus Batsch), citros (Citrus spp.) e videira (Vitis vinifera L.). Outro iniciador que obteve destaque foi o OSSR17 (Figura 1 B).
Trabalhos realizados anteriormente no Brasil mostraram diversidade nas populações de $X$. fastidiosa, em citros, em outras regiões do país (Coletta-Filho \& Machado, 2003; Lin et al., 2005).

O número de loci por população variou de 6 (REC1) a 14 (LIT2), com média de 10,22 (Tabela 1). As populações do Recôncavo Sul apresentaram número médio de loci de 7,75 , porém inferior ao encontrado entre as populações do Litoral Norte $(12,2)$. As amostras de São Paulo apresentaram 13 loci de SSR. As únicas populações que apresentaram loci exclusivos foram a REC2 e a LIT3, com um loci exclusivo em cada uma. O índice de polimorfismo variou entre $13,64 \%$ (REC1) e 59,09\% (LIT2), com média de $37,88 \%$ para as duas regiões. De modo geral, as populações do Recôncavo Sul apresentaram menores índices médios de polimorfismo $(22,72 \%)$ do que as do Litoral Norte $(48,86 \%)$. As populações que apresentaram os menores índices de polimorfismo (REC1 e REC4) também apresentaram os menores índices de diversidade genética, o que confirma sua baixa diversidade genética. As populações LIT2 e LIT4, com os maiores percentuais de polimorfismo, também foram as mais diversificadas geneticamente.

A partir dos dados da distância genética de Nei(1978), foram identificadas as populações mais similares (REC1 x REC3, REC1 x REC4 e REC3 x REC4) e as mais divergentes (REC1 x LIT1, REC2 x LIT1 e REC3 x LIT1) (Tabela 2). A similaridade genética média foi maior entre os isolados da mesma região: 0,976 entre as populações do Recôncavo Baiano e 0,966 entre as populações do Litoral Norte (Figura 2). A similaridade genética média entre os isolados das duas regiões foi de 0,73. Lin et al. (2005) também detectaram alto grau de similaridade entre os isolados de $X$. fastidiosa em citros.

A partir do dendograma obtido, verificou-se a formação de dois grandes grupos. O primeiro grupo foi composto pelas populações do Litoral Norte, e o segundo, pelas populações do Recôncavo Sul e pelas amostras de São Paulo. Diversos trabalhos também mostraram o agrupamento de isolados de $X$. fastidiosa em citros com relação à região geográfica de cultivo do hospedeiro (Mehta et al., 2001; Coletta-Filho \& Machado, 2003; Montero-Astúa et al., 2007; Almeida et al., 2008). Esse padrão foi esperado, ao se considerar a proximidade entre os pomares de uma mesma região. Destaca-se, também, que a população REC2 mostrou-

Pesq. agropec. bras., Brasília, v.49, n.1, p.26-33, jan. 2014

DOI: 10.1590/S0100-204X2014000100004 
se mais similar às amostras de São Paulo do que as demais populações da mesma região.

Apesar do alto polimorfismo dentro das populações, a maior parte da variação vem de diferenças entre populações (Tabela 3). As populações do Recôncavo Sul apresentaram um pool gênico distinto das populações do Litoral Norte (Figura 3). Dessa forma, a similaridade entre as populações do Recôncavo Sul e as amostras de São Paulo também foi confirmada pela análise de pools gênicos.

A população REC2 foi obtida de pomares do Município de Governador Mangabeira, primeiro
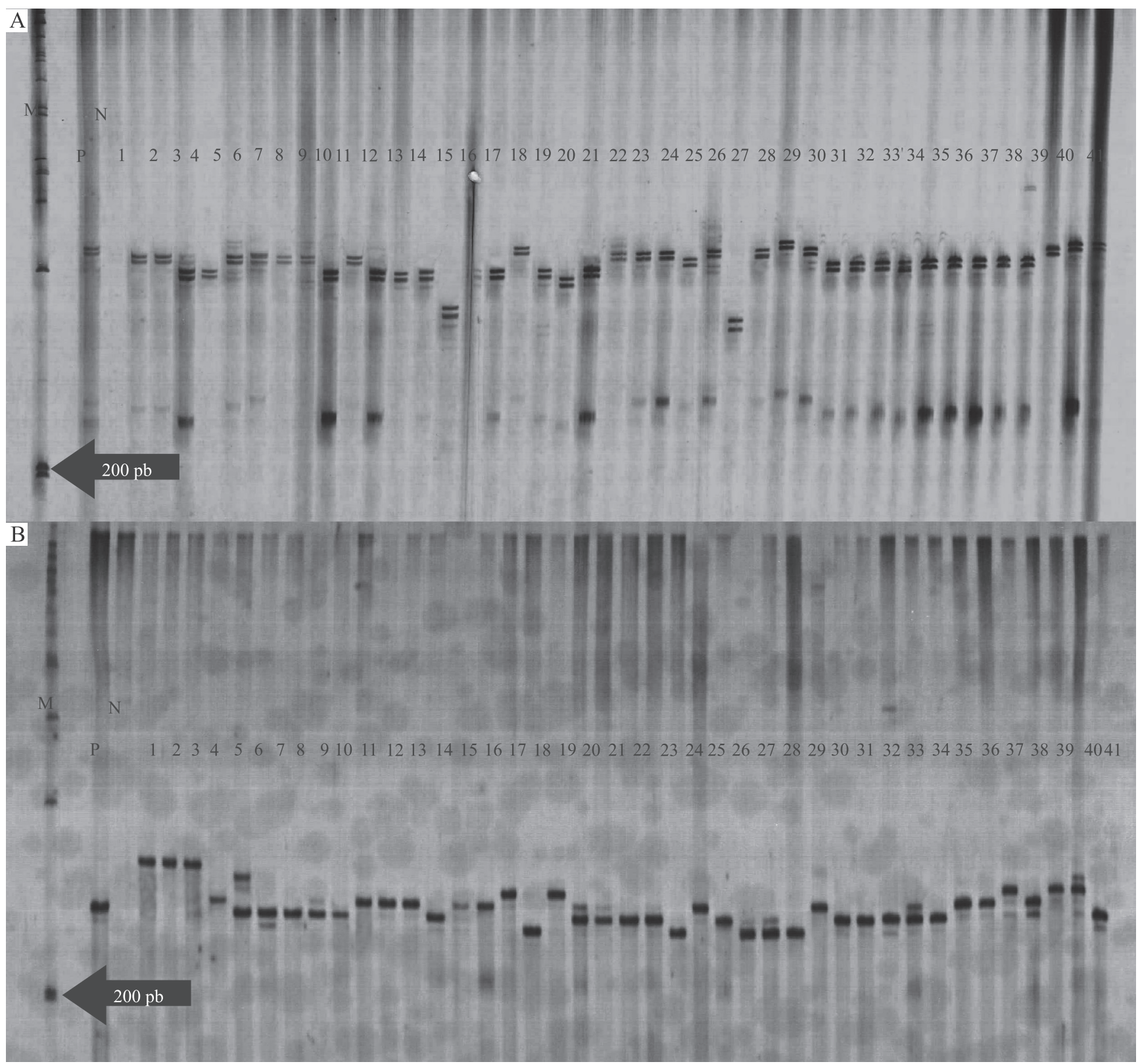

Figura 1. Produtos de amplificação do DNA de Xylella fastidiosa em gel de poliacrilamida a 5\%. A, amostras de campo da região do Recôncavo Sul da Bahia amplificadas com o iniciador CSSR20; B, amostras de campo do Litoral Norte da Bahia amplificadas com o iniciador OSSR17. M, marcador de peso molecular de 100 pares de bases (bp); P e N, amostra positiva e negativa para a bactéria, respectivamente. A seta indica o fragmento de $200 \mathrm{pb}$. 
local de detecção de $X$. fastidiosa no Recôncavo Sul da Bahia (Santos Filho et al., 2010). Isso indica que a introdução da bactéria nessa região pode ser decorrente da introdução mais recente a partir de mudas contaminadas do Estado de São Paulo e não da disseminação da bactéria existente na região do Litoral Norte (Santos Filho et al., 2010). Em 1980, quando houve detecção da CVC na região Nordeste, as análises de diversidade genética das amostras locais da bactéria revelaram que estas eram muito semelhantes aos isolados de São Paulo (Mehta et al., 2001; Laranjeira et al., 2008). Essa similaridade foi atribuída ao transporte de mudas contaminadas de São Paulo para Sergipe naquela ocasião (Mehta et al., 2001).
$\mathrm{Na}$ análise de diversidade haplotípica, foram identificados 13, 28 e 7 haplótipos para Recôncavo Sul, Litoral Norte e São Paulo, respectivamente, o que mostrou que as populações do Litoral Norte apresentam maior diversidade. A partir da rede de haplótipos, constatou-se maior diversidade genética na região do Litoral Norte do que na do Recôncavo Sul (Figura 4). Alguns haplótipos são compartilhados entre algumas populações, a exemplo do haplótipo H1, que está presente na população REC1, REC3 e REC4. Já o H2 foi compartilhado pelas populações REC1 e REC2. A entrada e o estabelecimento do patógeno na região do Litoral Norte ocorreram 13 anos antes que no Recôncavo Sul (Santos Filho et al., 2010), o que pode

Tabela 1. Regiões, populações do Recôncavo Sul (REC1 a REC4) e do Litoral Norte (LIT1 a LIT4), tamanho amostral, número de loci, número de haplótipos observados $\left(\mathrm{g}_{\mathrm{obs}}\right)$, percentagem de loci polimórficos $(\mathrm{P} \%)$, e índices de Stoddart e Taylor $(\mathrm{G})$ e Hills $\left(\mathrm{N}_{1}\right)^{(1)}$.

\begin{tabular}{|c|c|c|c|c|c|c|}
\hline \multirow[t]{2}{*}{ Região/População } & \multirow[t]{2}{*}{ Tamanho da amostra } & \multirow[t]{2}{*}{ Número de loci } & \multicolumn{2}{|c|}{ Índices de riqueza } & \multicolumn{2}{|c|}{ Índices de diversidade } \\
\hline & & & gobs & $\mathrm{P}(\%)$ & $\mathrm{G}$ & $\mathrm{N}_{1}$ \\
\hline \multicolumn{7}{|l|}{ Recôncavo Sul } \\
\hline REC1 & 10 & 6 & 3 & 13,64 & $1,85(0,99-2,71)^{(1)}$ & $2,23(1,67-3,15)$ \\
\hline REC2 & 10 & 10 & 6 & 36,36 & $3,33(1,59-5,07)$ & $4,47(2,69-6,25)$ \\
\hline REC3 & 10 & 8 & 6 & 22,73 & $4,17(2,46-5,88)$ & $5,00(3,35-6,65)$ \\
\hline REC4 & 11 & 7 & 4 & 18,18 & $2,20(1,10-3,30)$ & $2,81(1,63-3,99)$ \\
\hline Total & 41 & $7,75^{(2)}$ & 15 & $22,72^{(2)}$ & $4,34(2,42-6,26)$ & $7,65(5,24-10,06)$ \\
\hline \multicolumn{7}{|l|}{ Litoral Norte } \\
\hline LIT1 & 10 & 9 & 5 & 31,82 & $4,17(2,92-5,42)$ & $4,50(3,27-5,73)$ \\
\hline LIT2 & 10 & 14 & 9 & 59,09 & $8,33(6,31-10,35)$ & $8,70(6,66-10,74)$ \\
\hline LIT3 & 10 & 13 & 9 & 54,55 & $7,12(4,96-9,28)$ & $8,15(5,95-10,35)$ \\
\hline LIT4 & 11 & 12 & 10 & 50,00 & $10,00(7,90-12,10)$ & $10,00(7,94-12,06)$ \\
\hline Total & 41 & $12,2^{(2)}$ & 29 & $48,86^{(2)}$ & $21,83(17,62-26,04)$ & $25,42(21,68-29,16)$ \\
\hline Estado da Bahia & 82 & & 44 & 22 & $14,49(8,98-20,00)$ & $27,88(22,71-33,05)$ \\
\hline Média geral & & 10,22 & & 37,88 & & \\
\hline
\end{tabular}

${ }^{(1)}$ Números entre parênteses indicam o intervalo de confiança calculado por 'bootstrap' com 1.000 repetições. ${ }^{(2)}$ Média.

Tabela 2. Matriz de similaridade genética de $\mathrm{Nei}^{(1)}$ entre populações do Recôncavo Sul (REC1 a REC4) e do Litoral Norte (LIT1 a LIT4) do Estado da Bahia e de amostras do Estado de São Paulo (SPO), com base em dados SSR.

\begin{tabular}{|c|c|c|c|c|c|c|c|c|}
\hline & REC2 & REC3 & REC4 & LIT1 & LIT2 & LIT3 & LIT4 & SPO \\
\hline REC1 & 0,968 & 0,988 & 0,991 & 0,699 & 0,718 & 0,718 & 0,740 & 0,893 \\
\hline REC2 & & 0,967 & 0,952 & 0,708 & 0,736 & 0,736 & 0,757 & 0,891 \\
\hline REC3 & & & 0,992 & 0,717 & 0,728 & 0,731 & 0,745 & 0,891 \\
\hline REC4 & & & & 0,723 & 0,736 & 0,735 & 0,754 & 0,891 \\
\hline LIT1 & & & & & 0,949 & 0,972 & 0,963 & 0,731 \\
\hline LIT2 & & & & & & 0,964 & 0,980 & 0,783 \\
\hline LIT3 & & & & & & & 0,969 & 0,754 \\
\hline LIT4 & & & & & & & & 0,812 \\
\hline
\end{tabular}

${ }^{(1)} \mathrm{O}$ índice de similaridade genética de Nei varia entre 0 (menos similar) e 1 (mais similar). 
explicar, em parte, a maior quantidade de haplótipos dessa região. Igualmente, a baixa diversidade das populações do Litoral Norte, associada à alta similaridade genética com os isolados provenientes do Estado de São Paulo, indicou introdução mais recente (efeito fundador) (Linde et al., 2010).

Coletta-Filho \& Machado (2003), ao analisar isolados de $X$. fastidiosa, obtidos de plantas de laranja doce com $\mathrm{CVC}$, provenientes de cinco regiões de São Paulo, observaram maior diversidade da bactéria na região noroeste do Estado. De acordo com esses autores, esse comportamento provavelmente está relacionado ao fato de aquela região também apresentar populações mais antigas da bactéria, uma vez que foi o primeiro foco de CVC detectado em São Paulo. Além disso, também foi a região que serviu à cultura cafeeira no passado, considerada a mais

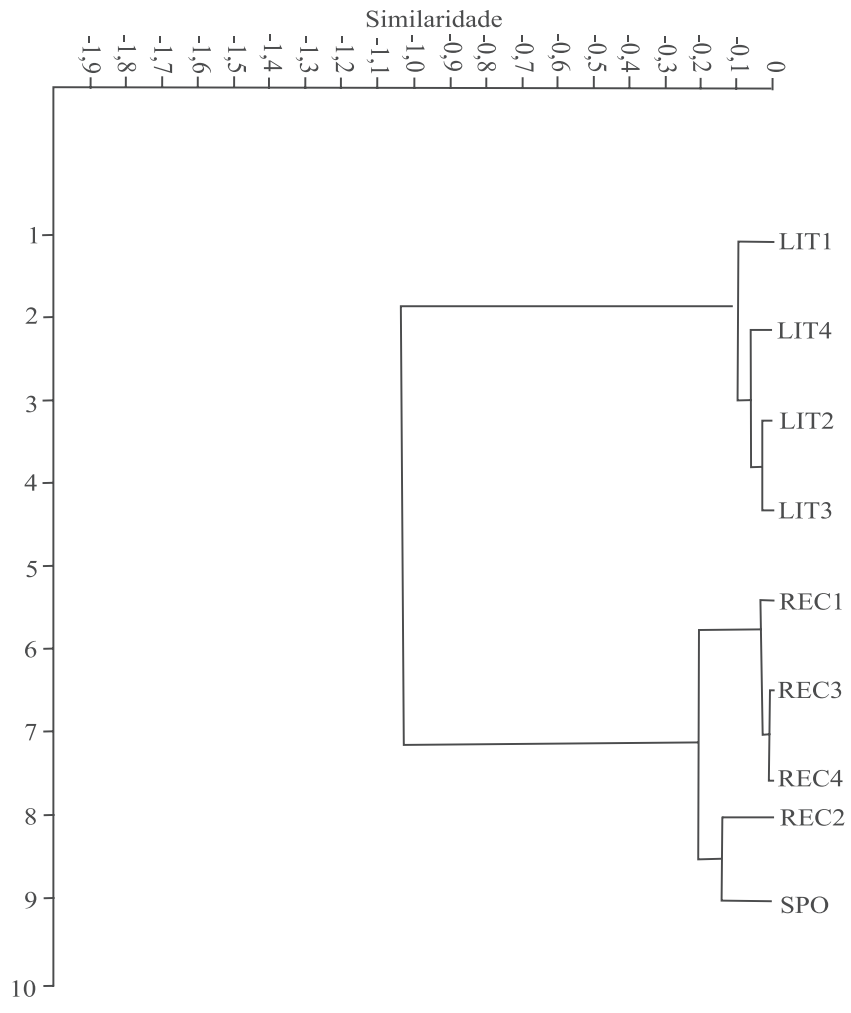

Figura 2. Análise de agrupamento de populações de Xylella fastidiosa das regiões do Recôncavo Sul (REC1 a REC4) e do Litoral Norte (LIT1 a LIT4) do Estado da Bahia, com base no índice de similaridade genética de Nei (1978), obtido a partir de marcadores SSR, e no método de Ward. SPO, amostras do Estado de São Paulo. provável fonte de infecção da bactéria para os citros (Almeida et al., 2008). Outra possível explicação para a maior diversidade genética de $X$. fastidiosa na região do Litoral Norte pode estar relacionada às múltiplas entradas de material propagativo infectado ao longo do tempo. Situação semelhante ocorreu na década de 1980, quando houve detecção da CVC na região Nordeste do Brasil (Mehta et al., 2001; Laranjeira et al., 2008), atribuída ao transporte de mudas contaminadas de São Paulo para Sergipe (Mehta et al., 2001).

As informações geradas sobre a diversidade de $X$. fastidiosa na Bahia poderão servir de subsídio para elaboração de estratégia de manejo regional da CVC mais eficiente. Os resultados das análises moleculares são indicativos de que mais de um evento de introdução do patógeno ocorreu no Estado da Bahia, o que serve de alerta para as autoridades fitossanitárias e reforça a necessidade de manutenção de barreiras, principalmente ao se considerar a possibilidade de recombinação entre as populações da Bahia e a introdução de novas variantes vindas de outros estados produtores.

Tabela 3. Análise de variância molecular entre as populações de Xylella fastidiosa provenientes do Recôncavo Sul e do Litoral Norte do Estado da Bahia, com base em marcadores SSR.

\begin{tabular}{lccccc}
\hline Fonte de variação & $\begin{array}{c}\text { Graus de } \\
\text { liberdade }\end{array}$ & $\begin{array}{c}\text { Soma dos } \\
\text { quadrados }\end{array}$ & $\begin{array}{c}\text { Componentes } \\
\text { de variância }\end{array}$ & $\begin{array}{c}\text { Percentual } \\
\text { de variação }\end{array}$ & $\begin{array}{c}\text { Valor } \\
\text { de } p\end{array}$ \\
\hline Entre populações & 8 & 133,864 & 1,505 & 53 & 0,001 \\
Dentro de populações & 83 & 111,918 & 1,348 & 47 & 0,001 \\
\hline Total & 91 & 245,783 & 2,854 & 100 & \\
\hline
\end{tabular}

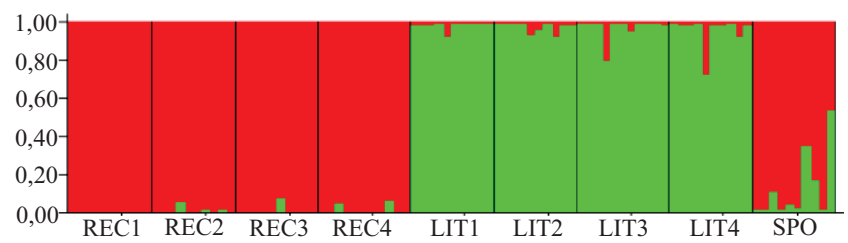

Figura 3. Análise de detecção de pools gênicos das populações de Xylella fastidiosa do Recôncavo Sul (REC1 a REC4) e do Litoral Norte (LIT1 a LIT4) do Estado da Bahia e de amostras de São Paulo (SPO), com uso do programa Structure 2.3. 


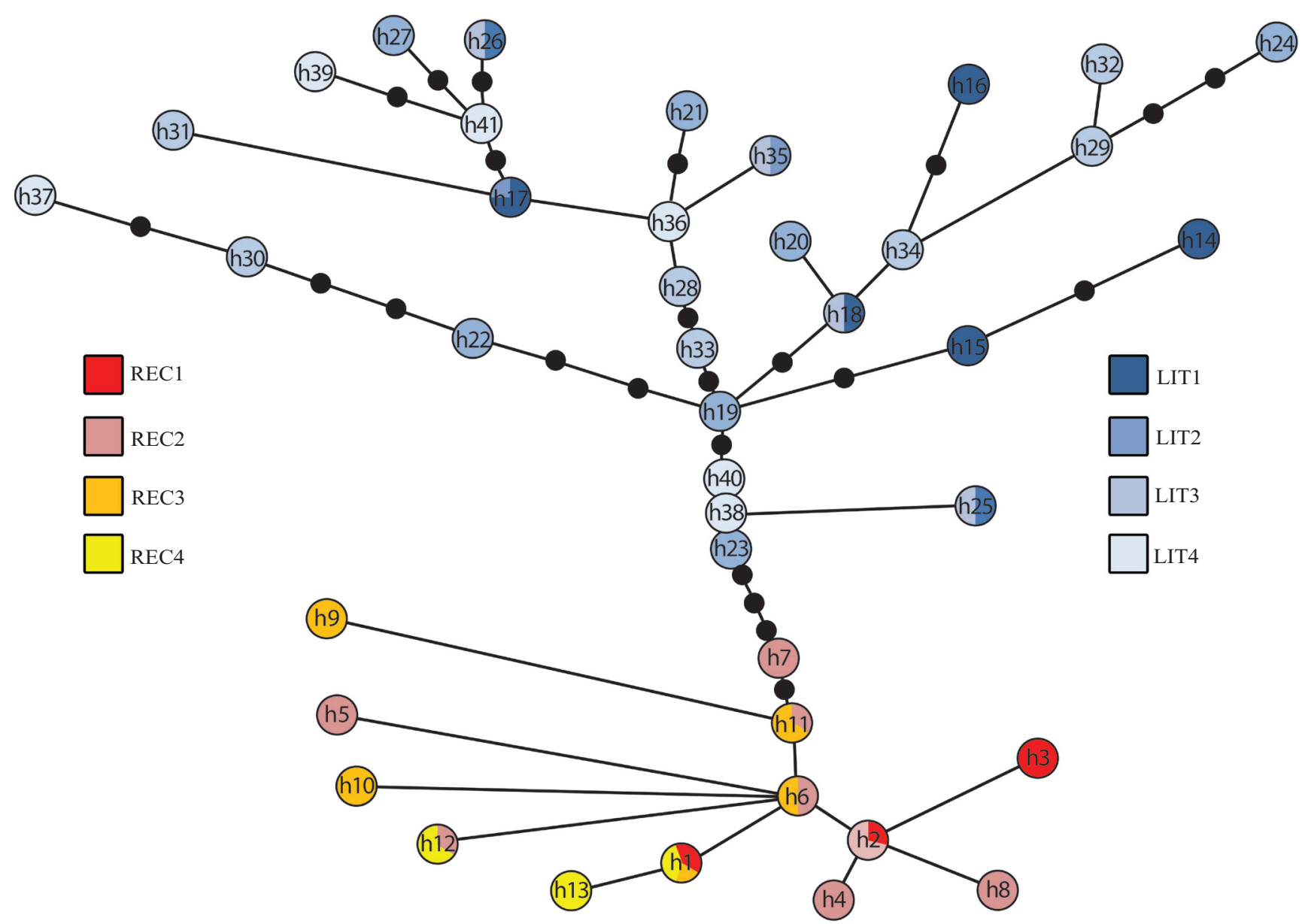

Figura 4. Rede de haplótipos (h) encontrados nas populações do Litoral Norte (LIT1 a LIT4) e do Recôncavo Sul da Bahia (REC1 a REC4). As cores indicam os pomares com presença dos haplótipos. Os círculos pretos indicam a distância entre os haplótipos em relação ao número de mutações pontuais.

\section{Conclusões}

1. As populações de Xylella fastidiosa presentes em citros no Estado da Bahia apresentam elevada diversidade genética, com base em dados de marcadores SSR.

2. As populações de $X$. fastidiosa nas regiões do Recôncavo Sul e do Litoral Norte da Bahia apresentam pools gênicos distintos e se agrupam geograficamente.

3. As populações de $X$. fastidiosa presentes na região do Litoral Norte apresentam maior diversidade genética do que as da região do Recôncavo Sul da Bahia.

\section{Agradecimentos}

À Fundação de Amparo à Pesquisa do Estado da Bahia (Fabesb), pelo apoio financeiro.

\section{Referências}

ALMEIDA, R.P.P.; NASCIMENTO, F.E.; CHAU, J.; PRADO S.S.; TSAI C.H.; LOPES, S.A.; LOPES, J.R.S. Genetic structure and biology of Xylella fastidiosa strains causing disease in citrus and coffee in Brazil. Applied and Environmental Microbiology, v.74, p.3690-3701, 2008. DOI: 10.1128/AEM.02388-07.

COLETTA-FILHO, H.D.; MACHADO, M.A. Geographical genetic structure of Xylella fastidiosa from citrus in São Paulo State, Brazil. Phytopathology, v.93, p.28-34, 2003. DOI: 10.1094/ PHYTO.2003.93.1.28.

DELlAPORTA, S.L.; WOOD, J.; HICKS, J.B. A plant DNA minipreparation: version II. Plant Molecular Biology Reporter, v.1, p.19-21, 1983. DOI: 10.1007/BF02712670.

EXCOFFIER, L.; LISCHER, H.E.L. Arlequin suite ver 3.5: a new series of programs to perform population genetics analyses under Linux and Windows. Molecular Ecology Resources, v.10, p.564-567, 2010. DOI: 10.1111/j.1755-0998.2010.02847.x. 
GRÜNWALD, N.J.; GOODWIN, S.B.; MILGROOM M.G.; FRY, W.E. Analysis of genotypic diversity data for populations of microorganisms. Phytopathology, v.93, p.738-746, 2003. DOI: 10.1094/PHYTO.2003.93.6.738.

HAMMER, O.; HARPER, D.A.T.; RYAN, P.D. PAST: Palaeontological Statistics software package for education and data analysis. Palaeontologia Electronica, v.4, p.1-9, 2001.

INSTITUTO BRASILEIRO DE GEOGRAFIA E ESTATÍSTICA. Produção brasileira de laranja em 2012. 2012. Disponível em $<$ http://www.cnpmf.embrapa.br/planilhas/Laranja_Brasil_2012. pdf $>$. Acesso em: 15 nov. 2013.

JANSE, J.D.; OBRADOVIC, A. Xylella fastidiosa: its biology, diagnosis, control and risks. Journal of Plant Pathology, v.92, p.35-48, 2010.

KISHI, L.T.; WICKERT, E.; LEMOS, E.G. de M. Evaluation of Xylella fastidiosa genetic diversity by fAFLP markers. Revista Brasileira de Fruticultura, v.30, p.202-208, 2008. DOI: 10.1590/ S0100-29452008000100037.

LARANJEIRA, F.F.; SILVA, L.G.; FONSECA, E.L.; SILVA, S.X.B.; ROCHA, J.B. SANTOS-FILHO, H.P.; LEDO, C.A.S.; HAU, B. Prevalence, incidence and distribution of citrus variegated chlorosis in Bahia, Brazil. Tropical Plant Pathology, v.33, p.339-347, 2008. DOI: 10.1590/S1982-56762008000500001.

LIN, H.; CIVEROLO, E.L.; HU, R.; BARROS, S.; FRANCIS, M.; WALKER, M.A. Multilocus simple sequence repeat markers for differentiating strains and evaluating genetic diversity of Xylella fastidiosa. Applied and Environmental Microbiology, v.71, p.4888-4892, 2005. DOI: 10.1128/AEM.71.8.4888-4892.2005.

LINDE, C.C.; LILES, J.A.; THRALL, P.H. Expansion of genetic diversity in randomly mating founder populations of Alternaria brassicicola infecting Cakile maritima in Australia. Applied and Environmental Microbiology, v.76, p.1946-1954, 2010. DOI: 10.1128/AEM.01594-09.

MEHTA, A.; LEITE JUNIOR, R.P.; ROSATO, Y.B. Assessment of the genetic diversity of Xylella fastidiosa isolated from citrus in Brazil by PCR-RFLP of the 16S rDNA and 16S-23S intergenic spacer and rep-PCR fingerprinting. Antonie van Leeuwenhoek, v.79, p.53-59, 2001. DOI: 10.1023/A:1010219811555.

MINSAVAGE, G.V.; THOMPSON, C.M.; HOPKINS, D.L.; LEITE, R.M.V.B.; STALL, R.E. Development of a polymerase chain reaction protocol for detection of Xylella fastidiosa in plant tissue. Phytopathology, v.84, p.456-461, 1994. DOI: 10.1094/ Phyto-84-456.

MONTERO-ASTÚA, M.; HARTUNG, J.S.; AGUILAR, E.; CHACÓN, C.; LI, W.; ALBERTAZZI F.J.; RIVERA, C. Genetic diversity of Xylella fastidiosa strains from Costa Rica, São Paulo,
Brazil, and United States. Phytopathology, v.97, p.1338-1347, 2007. DOI: 10.1094/PHYTO-97-10-1338.

NEI, M. Estimation of average heterozygosity and genetic distance from a small number of individuals. Genetics, v.89, p.583-90, 1978.

PARKER, J.K.; HAVIRD, J.C.; DE LAFUENTE, L. Differentiation of Xylella fastidiosa strains via multilocus sequence analysis of environmentally mediated genes (MLSA-E). Applied and Environmental Microbiology, v.78, p.1385-1396, 2012. DOI: 10.1128/AEM.06679-11.

PEAKALL, R.; SMOUSE, P.E. GenAlex 6.2: genetic analysis in Excel. Population genetic software for teaching and research. Molecular Ecology Notes, v.6, p.288-295, 2006. DOI: 10.1111/j.1 471-8286.2005.01155.x.

PRITCHARD, J.K.; STEPHENS, M.; DONNELLY, P. Inference of population structure using multilocus genotype data. Genetics, v.155, p.945-959, 2000.

R DEVELOPMENT CORE TEAM. R: a language and environment for statistical computing. R Foundation for Statistical Computing, 2011.

ROSSETTI, V.; DE NEGRI, J.D. Clorose variegada dos citros revisão. Citrus Research and Technology, v.32, p.61-66, 2011. DOI: $10.5935 / 2236-3122.20110007$.

SANTOS FILHO, H.P.; BARBOSA, C. de J.; LARANJEIRA, F.F.; SILVA, S.X. de B. Clorose variegada dos citros ameaça a citricultura do Recôncavo Sul. Cruz das Almas: Embrapa Mandioca e Fruticultura, 2010. 2p. (Embrapa Mandioca e Fruticultura Tropical. Citros em foco, 34).

SILVA, S.X. de S. Relatório técnico de levantamento de pragas da citricultura. Salvador: Agencia Estadual de Defesa Agropecuária da Bahia, 2013. 5p.

TEACHER, A.G.; GRIFFITHS, D.J. HapStar: automated haplotype network layout and visualization. Molecular Ecology Resources, v.11, p.151-153, 2011. DOI: 10.1111/j.1755-0998.2010.02890.x.

VARANI, A.M.; MONTEIRO-VITORELLO, C.B.; ALMEIDA, L.G.P. de; SOUZA, R.C.; CUNHA, O.L.; LIMA, W.C.; CIVEROLO, E.; VAN SLUYS, M.-A.; VASCONCELOS, A.T.R. Xylella fastidiosa comparative genomic database is an information resource to explore the annotation, genomic features, and biology of different strains. Genetics and Molecular Biology, v.35, p.149-152, 2012. DOI: 10.1590/ S1415-47572012005000019.

VASCONCELOS, A.P.; SANTOS FILHO, H.P.; BARBOSA, C.J.; MELO, R.L. Caracterização do isolado D-6 do vírus da tristeza dos citros após sucessivas propagações em laranja 'Pêra'. Magistra, v.16, p.91-95, 2004.

Recebido em 25 de outubro de 2013 e aprovado em 27 de dezembro de 2013

Pesq. agropec. bras., Brasília, 49, n.1, p.26-33, jan. 2014 DOI: 10.1590/S0100-204X2014000100004 